\title{
Identifikasi Lalat Buah yang Menyerang Buah Naga (Hylocereus sp.) di Kecamatan Batu Ampar, Kabupaten Tanah Laut Kalimantan Selatan
}

\author{
DOI 10.18196/pt.2016.063.107-111
}

\author{
Muhammad Indar Pramudi* dan Helda Orbani Rosa \\ Program Studi Proteksi Tanaman Fakultas Pertanian Universitas Lambung Mangkurat, \\ Jl. Brigjen. H. Hasan Basri, Kotak Pos 219, Banjarmasin, Kalimantan Selatan, 70123, Indonesia, Telp (0511) 54177 \\ *Corresponding author, e-mail: indar_pramudi@yahoo.com
}

\begin{abstract}
ABSTRAK
Saat ini identifikasi lalat buah yang menyerang buah naga di Kabupaten Tanah Laut belum pernah dilakukan. Penelitian ini bertujuan untuk mengetahui spesies lalat buah yang menyerang buah naga di Kecamatan Batu Ampar Kabupaten Tanah Laut Propinsi Kalimantan Selatan dan musuh alaminya. Buah naga yang menunjukkan gejala serangan lalat buah di lapang diambil dan diamati perkembangannya mulai dari larva hingga menjadi imago kemudian diidentifikasi. Berdasarkan hasil identifikasi menunjukkan bahwa lalat buah yang menyerang buah naga di Kecamatan Batu Ampar adalah Bactrocera dorsalis Hendel. Dalam penelitian ini ditemukan 1 parasitoid yaitu Aceratoneuro myiaindica (Hymenoptera: Eulophidae: Tetrastichinae) dan lima predator antara lain semut merah (Hymenoptera: Formicidae: Solenopsis), semut rangrang (Hymenoptera: Formicidae: Oecophylla), laba-laba (Arachnida: Lycosidae: Hogna), kumbang stafilinid (Coleoptera: Staphylinidae: Paederinae) dan cocopet (Dermaptera: Forficulidae: Forficula).

Kata kunci: Buah naga, Lalat buah, Parasitoid, Predator.
\end{abstract}

\begin{abstract}
Identification of fruit flies of dragon fruit in Tanah Laut has never been conducted. This research was aimed to identify fruit flies species of dragon fruit and its natural enemies in Batu Ampar, Tanah Laut, Kalimantan Selatan. The fruit flies attacking dragon fruit in the field was collected. Observation was performed on the development of the larvae until adult and finally emerging adult was identified as well as its parasitoid. The result showed that the obtained fruit flies was Bactrocera dorsalis Hendel and Aceratoneuro myiaindica (Hymenoptera: Eulophidae: Tetrastichinae) was found as the parasitoid. Five predators was found as its natural enemies, namely red ants (Hymenoptera: Formicidae: Solenopsis), rangrang ant (Hymenoptera: Formicidae: Oecophylla), spiders (Arachnida), kumbang stafilinid (Coleoptera: Staphylinidae: Paederinae) and earwig (Dermaptera: Forficulidae: Forficula).

Keywords: Dragon fruit, Fruit flies, Parasitoid, Predator
\end{abstract}

\section{PENDAHULUAN}

Ketersediaan buah naga masih langka di pasaran, dan mulai meluas dikenal di Indonesia pada awal tahun 2000-an yang saat itu didatangkan dari Thailand. Buah naga atau lazim juga disebut pitaya, menjadi salah satu buah yang populer di kalangan masyarakat. Buah yang termasuk kelompok kaktus atau famili Cactaceae ini sangat digemari oleh masyarakat untuk dikonsumsi.

Buah naga memilki nilai ekonomi yang cukup tinggi jika dibandingkan dengan buah yang lain. Hal ini menjadi peluang usaha bagi investor domestik untuk melakukan pembudidayaan buah naga dengan skala yang cukup besar. Beberapa sentra agribisnis buah naga yang mulai berkembang antara lain Malang, Delanggu, Kulonprogo, dan DI Yogyakarta (Purba, 2007). Untuk daerah Kalimantan Selatan, daerah penghasil buah naga berada di Kabupaten Tanah Laut. Kondisi iklim dan keadaan tekstur tanah di Tanah Laut mendukung untuk pengembangan agribisnis buah naga. Dimasa akan datang komoditas ini mempunyai prospek yang cerah untuk dikembangkan menjadi komoditas ekspor (Deptan, 2003).

Terdapat empat jenis buah naga yang dikembangkan yaitu buah naga daging putih (Hylocereus undatus), buah naga daging merah (Hylocereus polyrhizus), buah naga daging super merah ( $\mathrm{Hy}$ locereus costaricensis) dan buah naga kulit kuning daging putih (Selenicereus megalanthus). Masingmasing buah naga memiliki karakteristiknya 
sendiri. Dari buah naga yang dikembangkan tersebut buah naga Hylocereus polyrhizus lebih sering dibudidayakan karena memilki kelebihan tersendiri yaitu ukuran buah buah lebih besar dan warna daging lebih menarik. Sedangkan buah naga yang jarang dibudidayakan adalah buah naga Selenicereus megalanthus karena ukuran buah yang relatif kecil walaupun rasanya paling manis diantara jenis yang lain.

Lalat buah (Diptera: Tephritidae) merupakan hama yang memiliki arti penting bagi pertanian. Terdapat sekitar 4000 spesies lalat buah di dunia dan 35\% di antaranya merupakan hama penting pada buah-buahan termasuk di dalamnya buah-buahan komersial yang mempunyai nilai ekonomi tinggi. Informasi tentang keberadaan jenis-jenis lalat buah yang ada di suatu daerah perlu diketahui dan dilaporkan sebagai langkah antisipasi dan pengendalian pada tanaman buah yang dibudidayakan. Saat ini identifikasi lalat buah yang dapat menyerang buah naga di Kecamatan Batu Ampar, Kabupaten Tanah Laut belum pernah dilakukan, sehingga perlu dilakukan penelitian untuk mengetahui spesies lalat buah apa saja yang menyerang buah naga serta musuh alaminya. Adapun tujuan dari penelitian ini adalah untuk mengetahui spesies lalat buah yang menyerang buah naga di Kecamatan Batu Ampar, Kabupaten Tanah Laut serta musuh alaminya (predator dan parasitoid).

\section{BAHAN DAN METODE}

Penelitian ini merupakan penelitian deskriptif dengan metode survei dengan pengumpulan buah naga yang terserang lalat buah. Dari dua kebun buah naga yang memiliki hamparan kebun e" 5 ha. Lokasi pengambilan sampel sengaja ditempatkan di Kecamatan Batu Ampar Kabupaten Tanah laut karena sentra perkebunan buah naga di Kalimantan Selatan terdapat dilokasi ini. Sebanyak $5 \mathrm{~kg}$ buah yang terdapat gejala serangan lalat buah secara sengaja. Identifikasi lalat buah dan musuh alami dilakukan di Laboratorium Entomologi Jurusan Hama dan Penyakit Tumbuhan Fakultas Pertanian Universitas Lambung Mangkurat. Penelitian dilakukan pada bulan April-Juni 2015.

\section{Pengumpulan Buah Terserang Lalat Buah}

Buah yang diambil adalah buah yang busuk dengan bintik hitam di permukaan kulit buahnya dan terdapat larva atau ulat di dalamnya. Buah yang diambil per lokasi sebanyak 5 kg. Pengambilan buah dilakukan sebanyak tiga kali dengan interval waktu satu minggu. Buah naga yang didapatkan kemudian dimasukkan ke dalam stoples plastik dengan ukuran diameter $15 \mathrm{~cm}$, tinggi $19 \mathrm{~cm}$, yang diletakkan di laboratorium dan diamati setiap hari sampai muncul imago (Asrida et al, 2001 dan Swibawa et al, 2003). Imago yang muncul diidentifikasi hingga spesies (jika memungkinkan) selanjutnya dikategorikan berdasarkan statusnya.

\section{HASIL DAN PEMBAHASAN}

Berdasarkan hasil identifikasi imago lalat buah yang menyerang buah naga adalah Bactrocera dorsalis Hendel dengan skutum berwarna hitam, mesonotum hitam, pita lateral kuning pada mesonotum memanjang kedekat rambut supra alar, dua pasang rambut pada fronto orbital bagian dalam, dua rambut pada skutelum. Sayap tidak mempunyai noda atau bercak vena melintang, pita hitam memanjang pada garis costa dan anal. Pada abdomen terlihat jelas batas-batas antar ruas (tergit), terdapat rambut-rambut menyerupai sikat (pecten) padatergit ke-3 dan terdapat bercak yang agak memudar pada tergit ke-5. Abdomen berwarna coklat dengan pita hitam pada tergit ke-2 dan tergit ke-3, pita hitam sempit ditengah tergit ke 3-5 (Gambar 1). 


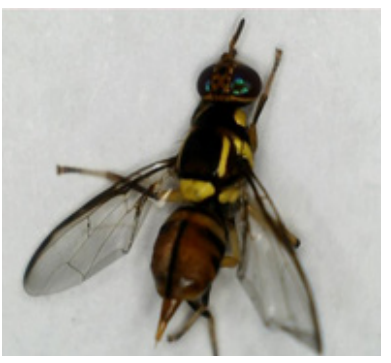

Lalat Jantan

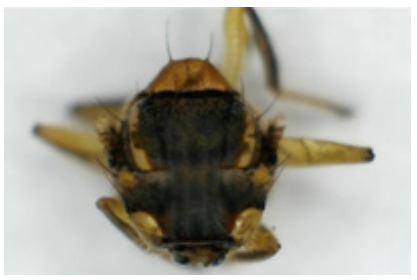

Torak

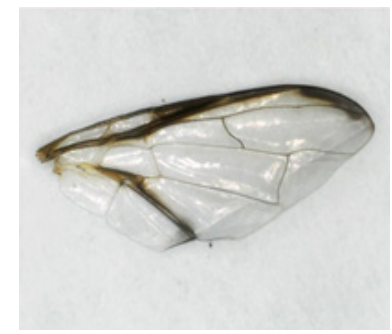

Sayap

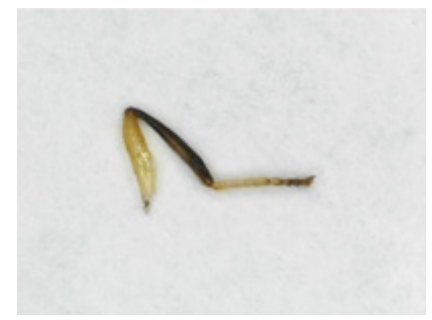

Kaki Belakang

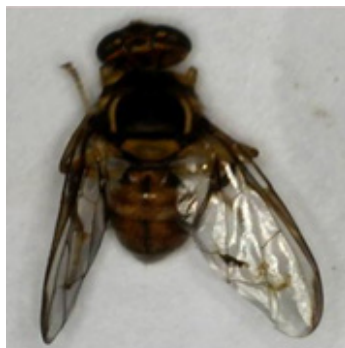

Lalat Betina

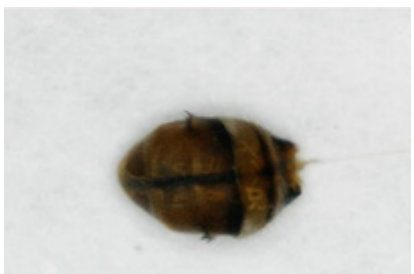

Abdomen

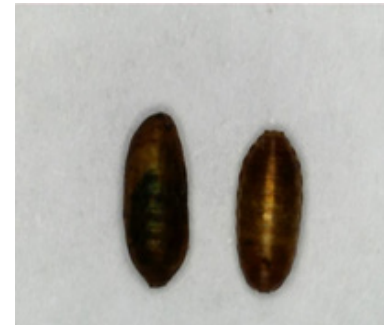

Pupa

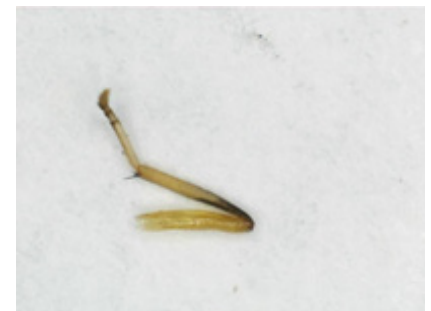

Kaki Tengah

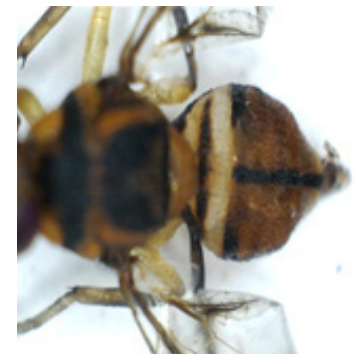

Torak dan Abdomen

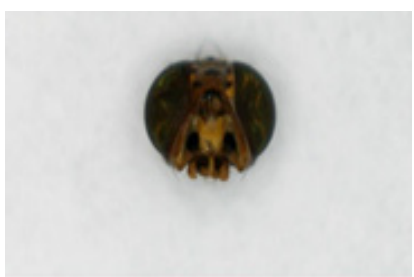

Kepala

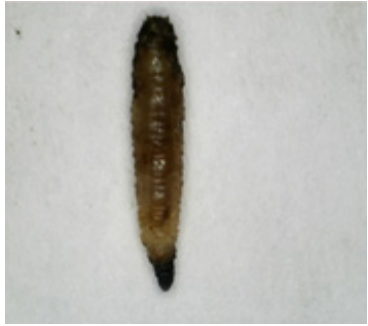

Larva

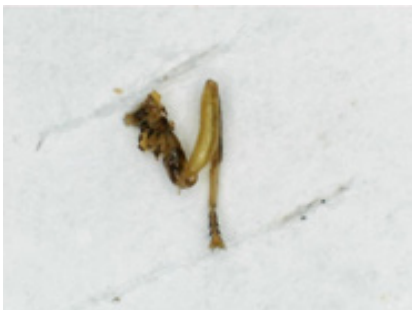

Kaki Depan

Gambar 1. Morfologi Bactrocera dorsalis Hendel yang Pemeliharaan Buah Naga Terserang Lalat Buah 
Lalat buah menyerang buah naga dengan meletakkan telur pada jaringan di bawah kulit buah. Telur menetas menjadi larva dan mulai memakan daging buah sampai terjadi proses pembusukan. Serangan serius dan meluas dapat menyebabkan gagal panen. Lalat buah (Diptera:Tephritidae) merupakan salah satu hama potensial yang sangat merugikan produksi buah-buahan dan sayuran, baik secara kuantitas maupun kualitas (Rouse et al., 2005; Copeland et al., 2006). Hama ini menjadi hama utama pada buah-buahan di seluruh dunia (Pena, et al., 1998; Vargas et al., 2005), termasuk di Indonesia (Sodiq, 1993; Soesilohadi, 2002; Siwi et al., 2006). Dari beberapa jenis lalat buah, B. dorsalis Complex adalah yang paling banyak anggotanya (White dan Elson-Harris, 1992; Sodiq, 1993; Soesilohadi, 2002; Revis et al., 2004; Robacker et al., 2005). B. dorsalis Hendel dapat menyerang lebih dari 20 jenis buah antara lain belimbing, mangga, jeruk, jambu, pisang susu, pisang raja, serai, cabai merah.

Pada saat pengambilan buah, ditemukan beberapa jenis predator pada saat pengambilan buah dan parasitoid pada saat pemeliharaan buah yang terserang dari lapang (Tabel 1). Parasitoid yang ditemukan adalah Aceratoneuro myiaindica (Hymenoptera: Eulophidae: Tetrastichinae) dan lima predator yaitu semut merah dan semut rangrang (Hymenoptera: Formicidae), laba-laba (Arachnida), kumbang Stafilinid (Coleoptera: Staphylinidae) dan cocopet (Dermaptera). Menurut Direktorat Perlindungan Tanaman Hortikultura (2008) parasitoid yang sudah di identifikasi di Indonesia adalah Fopius (Biosteres sp.) dan Opius sp. (family Braconidae), Fopius sp. Parasitoid tersebut dapat ditemukan pada lalat buah yang menyerang mangga, belimbing dan jambu biji dengan parasitasi 5,17-10,31\% sedangkan Opius sp banyak ditemukan pada lalat buah yang menyerang mangga dengan tingkat parasitasi $0-6,8 \%$.

Tabel 1. Parasitoid dan predator yang diduga menjadi musuh alami lalat buah pada saat pengambilan buah dan pemeliharaan larva lalat buah dari buah terserang di lapang

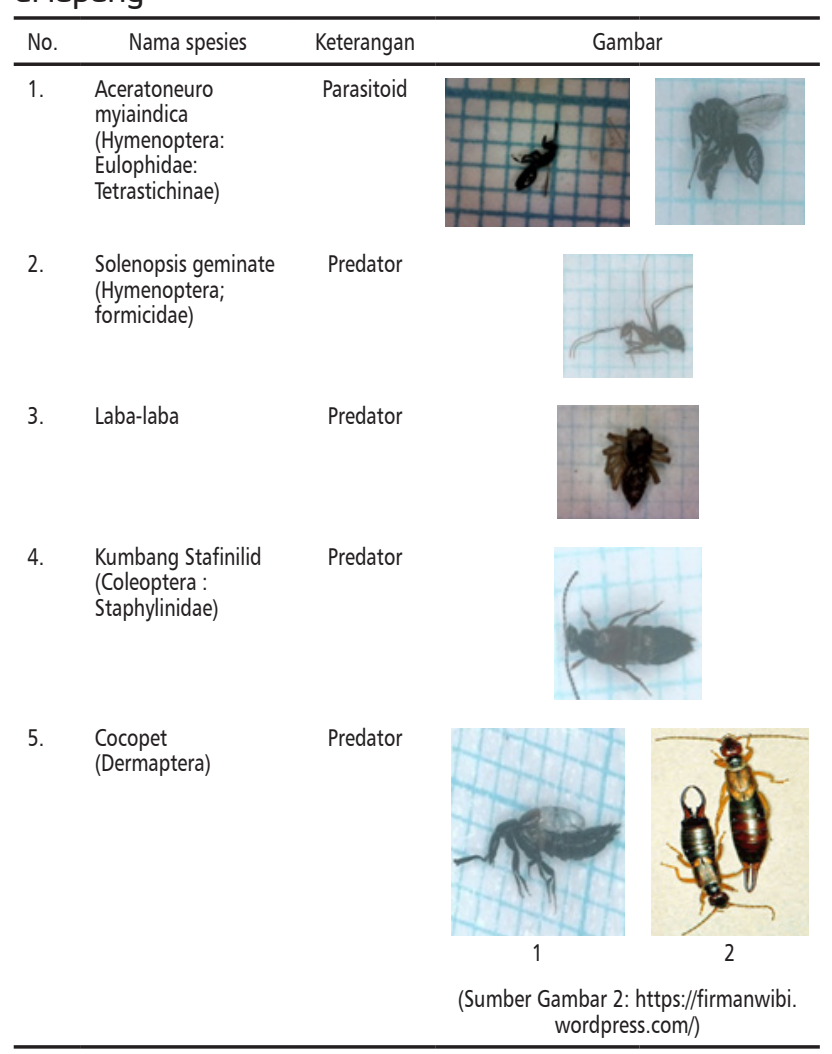

Predator lalat buah yang umum ditemukan adalah semut (Hymenoptera: Formicidae), labalaba (Arachnida), kumbang Stafilinid (Coleoptera: Staphylinidae) dan cocopet (Dermaptera). Pengendalian secara biologis (pemanfaatan musuh alami atau agens hayati) menggunakan parasitoid maupun predator untuk mengendalikan atau menekan populasi lalat buah sudah banyak dilakukan, tetapi belum diterapkan di Indonesia. Malaysia telah banyak memanfaatkan parasit dari famili Braconidae yang mempunyai potensi parasitasi sebesar 57\%, sedangkan di Italia potensinya 80-90\%. Diachasmimorpha kraussii (Hymenoptera: Braconidae) dilaporkan merupakan 
salah satu parasitoid yang dilaporkan memarasit larva larva lalat buah Bactrocera tryoni (Froggatt), B. neohumeralis, B. cacuminata, B. jarvisi, B. kraussi, B. halforgiae dan beberapa spesies lalat buah lain di Australia. Jenis Predator lalat buah yang secara luas telah dilaporkan adalah semut, laba-laba, kumbang stafilinid dan cocopet (Dermaptera). Jenis patogen yang banyak menyerang pupa lalat buah adalah Beauveria sp. (Soesilohadi, 2002).

Melimpahnya suatu populasi organisme, selain disebabkan oleh faktor inang dan lingkungan juga dipengaruhi oleh musuh alaminya (predator dan parasitoid). Musuh alami mempunyai peranan penting dalam pengaturan populasi lalat buah di lapang. Populasi lalat buah berbeda antara satu tempat dengan tempat lainnya karena berkaitan dengan keberadaan inang (buah), jumlah inang dan adaptasinya dengan lingkungannya. Suatu area yang luas akan mendukung pertambahan populasi spesies karena tersedianya sumber makanan dan habitat yang sesuai (Rouse et al, 2005).

\section{SIMPULAN}

Hasil identifikasi imago lalat buah yang menyerang buah naga adalah Bactrocera dorsalis Hendel. Parasitoid yang ditemukan adalah Aceratoneuro myiaindica (Hymenoptera: Eulophidae: Tetrastichinae). Predator yang ditemukan yaitu semut merah (Hymenoptera: Formicidae: Solenopsis), semut rangrang (Hymenoptera: Formicidae: Oecophylla), laba-laba (Arachnida: Lycosidae: Hogna), kumbang stafilinid (Coleoptera: Staphylinidae: Paederinae) dan cocopet (Dermaptera: Forficulidae: Forficula).

\section{DAFTAR PUSTAKA}

Asrida, E., F.X. Susilo dan L. Wibowo. 2001. Respons Berbagai Jenis Lalat Buah Belimbing Terhadap Pembungkusan Buah. J. Penel. Sains Tek. 7 (1): 76-86.
Copeland, R. S., R. A. Wharton, Q. Luke, M. D. Meyer, S. Lux, N. Zenz, P. Machera and M. Okumu. 2006. Geographic Distribution, Host Fruit, and Parasitoids of African Fruit Fly Pest Ceratitis anonae, Ceratitis cosyra, Ceratitis fasciventris, and Ceratitis rosa (Diptera: Tephritidae) in Kenya. Ann. Entomol. Soc. Am. 99(2): 261-278.

Deptan. 2003. Pengembangan Agribisnis Buah Naga (Dragon Fruit) Indonesia dalam Mencapai Pasar Ekspor. http://agribisnis.deptan.go.id/index.php?files=berita_detail\&id=412.

Pena, J.E., A.I. Mohyoudin, M. Wysoki. 1998. A Review of the Pest Management Situation in Mango Agroecosystems. J. Phytoparasitica. 26 (2): 1-20.

Purba, F.H.K. 2007. Potensi buah naga dalam pengembangannya di Indonesia. Peluang Bisnis Bibit Buah Agrimart.

Revis, H.C., N.W. Miller, R.I.Vargas. 2004. Effects of Aging Dilution on Attractionand Toxicyti og GF-120 Fruit Fly Bait Spray for Melon Fly Control in Hawaii. J.Econ. Entomol. 97(5): 16591665.

Robacker, D.C., D. Czokajlo. 2005. Efficacy of Two Synthetic Food-Odor Lures forMexican Fruit flies (Diptera : Tephritidae) Is Determined by Trap Type. 2005. J.Econ. Entomol. 98(5): 1517-1523.

Rouse P., P.F. Duyck, S. Quilici, P. Ryckewaert. 2005. Adjustment of Field CageMethodology for Testing Food Attractants for Friut Flies (Diptera : Tephritidae).Ann. Entomol. Soc. Am. 98(3) : 402-408.

Siwi S.S., P. Hidayat dan Suputa, 2006. Taksonomi dan Bioekologi Lalat Buah Penting, Bactrocera spp. (Diptera : Tephritidae) di Indonesia. Balai Besar Penelitian dan Pengembangan Bioteknologi dan Sumberdaya Genetik, Bogor.

Sodiq, M. 1993. Aspek biologi dan sebaran populasi lalat buah pada tanaman mangga dalam kaitan dengan pengembangan model pengendalian hama terpadu. Disertasi. Program Pascasarjana. Universitas Airlangga. Surabaya.

Soesilohadi, R.C.H. 2002. Dinamika populasi lalat buah, Bactrocera carambolae Drew and Handcock (Diptera : Tephritidae). Disertasi. Program Pascasarjana. Institut Teknologi Bandung. Bandung.

Swibawa, I.G., F.X. Susilo, I. Murti dan E. Ristiyani. 2003. Serangan Dacus cucurbitae (Diptera: Trypetidae) pada buah mentimun dan pare yang dibungkus pada saat pentil. J. HPT Tropika 3 (2): 43 -46.

Vargas R.I., J.D. Stark, B. Mackey and R. Bull. 2005. Weathering trials of amulet cue-lure and amulet methyl eugenol "attractand-kill" stations with male melonflies and oriental fruit flies (diptera:tephritidae) in Hawai. J. Econ. Entomol. 98 (5): 1551-1559.

White, I.M. and M.M.E.Harris, 1992. Fruit flies of economic significance : their identification and bionomics. CAB International. Wallingford. Oxon. United Kingdom. 